\title{
Perspectivas para a Psicologia do Trânsito
}

\author{
Iara Picchioni Thielen \\ Universidade Federal do Paraná
}

\begin{abstract}
RESUMO
Este artigo aborda a Psicologia de Trânsito, a partir das atividades desenvolvidas pelo Núcleo de Psicologia do Trânsito da Universidade Federal do Paraná (NPT-UFPR), que propiciaram a criação da Linha de Pesquisa Psicologia do Trânsito: Avaliação e Prevenção. A centralidade exercida pela avaliação psicológica é referenciada, bem como a indicação da ampliação de perspectivas de investigação, a partir de novas pesquisas e intervenções integradas. A abordagem sistêmica permite a compreensão do comportamento humano no trânsito, indicando a complexidade das interações que se estabelecem entre insumos e processos que resultam na adoção de comportamentos de risco, que geram danos a si e aos outros. A tomada de decisão no trânsito se torna um dos aspectos centrais, demandando investigações que elucidem a maneira como ocorre e como pode ser orientada, a partir do estudo de fatores que contribuem para comportamentos mais seguros e que incorporem a dimensão coletiva intrínseca ao trânsito. Destaque especial é dado às pesquisas que aprofundam a compreensão do comportamento humano em situação de trânsito a partir do referencial da percepção de riscos.
\end{abstract}

Palavras-chave: psicologia do trânsito; percepção de risco; veículos automotores; assunção de risco.

\section{ABSTRACT \\ Perspectives on Traffic Psychology}

This paper focuses on Traffic Psychology, based on the activities carried out in the Traffic Psychology Laboratory at the Federal University of Paraná, Brazil. Those activities lead to the creation of the research program "Traffic Psychology: Evaluation and Prevention". The present paper refers to the psychological evaluation process extensively used in Brazil nowadays, as well as it shows the need of widening the studies perspectives, through new interrelated research and intervention. The General System Theory approach allows the understanding of human behavior in traffic situations, showing the complexity of the interactions between inputs and processes that result in risk behavior which provides damages to oneself and to the others. The decision making process in traffic situations becomes one of the main points, demanding investigations on how it occurs and how it can be oriented, studying the factors that contribute to safer behaviors, focused on the collective dimension of traffic. Special attention is given to research that deepen the understanding of human behavior in traffic situations, under the risk perception point of view.

Keywords: traffic psychology; risk perception; automotive vehicle; risk taking.

O que é Psicologia do Trânsito? De que trata? Quais suas bases orientadoras? Essas e muitas outras questões permeiam não só a formação dos psicólogos, mas, principalmente, instigam a curiosidade de tantos quantos se defrontam com a parcela de responsabilidade atribuída ao comportamento humano nas situações de violência no trânsito. E a Psicologia tem sido chamada pela Engenharia, pelo Direito, pela Fiscalização, pelos legisladores, pelos juízes, pelos peritos, pela Sociologia, pela Ergonomia, além de tantas outras áreas de conhecimento e, principalmente pela mídia, a "dar explicações" sobre as motivações para ações irrefletidas que resultam em danos: "Afinal, por que as pessoas se comportam dessa maneira, provocando tantos danos evitáveis?"
O trânsito é considerado pela Organização Mundial da Saúde como um problema de saúde pública, e abordado dessa forma por todos os que se debruçam sobre a busca de soluções para a violência consentida:

Las lesiones causadas por el tránsito constituyen un importante problema de la salud pública, pero desatendido, cuya prevención eficaz y sostenible exige esfuerzos concertados. De todos los sistemas con los que las personas han de enfrentarse cada día, los del tránsito son los más complejos y peligrosos. (Organización Mundial de la Salud, 2010)

O trânsito também está constantemente na mídia, de maneira corriqueira, noticiando todos os dias os mortos contabilizados. Mas há um grande contingente 
de mutilados desconhecidos e não contabilizados, uma vez que o dano não atinge apenas aquele que morre ou aquele que mata, mas incontáveis pessoas com sequelas ou mutilações, estendendo os danos pelas famílias de ambos, pelas organizações que deixam de produzir pela ausência de trabalhadores que se envolveram na violência no trânsito, pela sociedade em geral. É possível destacar também o sofrimento que não pode ser contabilizado.

E, para mais além dos mortos e mutilados, há o sofrimento não dimensionado de todos aqueles que se defrontam com a morte violenta no trânsito: desde a vítima e sua família, passando pelo algoz e sua família. Inúmeras outras pessoas vivenciam sofrimento na tarefa de resgatar corpos, pedaços de corpos, pessoas mutiladas, pessoas traumatizadas, vítimas ou algozes. Também há sofrimento nas pessoas que têm como tarefa registrar as ocorrências e mensurar o dano, coletando dados e registrando informações que servirão de base para esclarecimento dos casos, bem como as pessoas que atendem nas Delegacias de Delitos de Acidentes de Trânsito e têm a árdua tarefa de se defrontar com os danos aos sobreviventes e encaminhar as investigações, por vezes exercendo o papel de orientadores das famílias até mesmo na dor. As pessoas da área de saúde que atuam visando aplacar a dor, seja nos atendimentos de emergência seja nos hospitais, que "costuram os pedaços" e enfrentam a batalha contra a morte e as sequelas que poderiam ter sido evitadas, também são vítimas do sofrimento que pretendem combater. $\mathrm{O}$ dano é estendido às pessoas que conceberam, planejaram e implantaram dispositivos de segurança, às pessoas que atuam com a gestão do sistema trânsito e se defrontam com o fracasso de ações, às pessoas que atuam nas tradicionais vertentes da segurança do trânsito (engenharia, educação e esforço legal); aos pesquisadores que não têm encontrado respostas para orientar ações educativas ou de outros âmbitos a partir de estudos, em decorrência da amplitude de variáveis e, portanto, da complexidade de que se reveste o comportamento humano, entre tantas outras pessoas envolvidas nesse grave problema de Saúde Pública (Marin \& Queiróz, 2000) que é o trânsito.

Já é possível visualizar algumas respostas às questões iniciais propostas para instigar o debate sobre o tema: a psicologia do trânsito tem como tarefa compreender e intervir no comportamento humano no trânsito. É a psicologia aplicada às situações de trânsito, do qual todos são participantes. Portanto, ela é mais ampla do que se pensa. À psicologia cabe investigar diferentes aspectos relacionados ao comporta- mento humano, no exercício do direito de ir e vir com segurança de cada um e de todos, e em todas as situações nas quais o comportamento humano exerce influência.

Já é possível também identificar algumas vertentes de investigação e intervenção junto a cada um dos grupos de pessoas envolvidas nas mortes violentas no trânsito. Cada uma das pessoas vivencia sofrimentos que devem ser compreendidos e orientados. E a psicologia também tem referenciais para atuar com o sofrimento humano em diferentes perspectivas. Mas essa possibilidade de atuação se refere a um "depois". Depois que um ato imprudente, imperito ou negligente foi perpetrado. Mas à psicologia cabe também prover respostas em relação aos fatores que orientam as decisões para agir "dessa ou daquela" maneira, adotando comportamentos mais ou menos arriscados. Ou seja, a psicologia tem também um papel importante na prevenção da violência no trânsito.

A trajetória histórica da psicologia também indica uma atuação voltada para a avaliação psicológica utilizada para o processo de habilitação de condutores, com o intuito de identificar características psicológicas que poderiam verificar condições prévias para o exercício da atividade de dirigir veículos (Hoffman \& Cruz, 2003; Monterde i Bort, 2008; Risser, 2004; Rozestraten, 1988).

Em outra vertente, mas sem esgotar as possibilidades de atuação, há o campo de estudos da psicologia voltado para todas as relações que se estabelecem entre os sujeitos e seus lugares, a análise da mobilidade urbana, das escolhas individuais dos modais de transporte, dos posicionamentos ideológicos, da força grupal e de fatores interpessoais orientando percepções e decisões acerca da ocupação de espaços e da vinculação dos sujeitos. O fortalecimento das identidades e o desenvolvimento de vínculos e concepções compartilhadas em direção à convivência harmônica a partir das diferenças também pode ser foco de investigação e intervenção, principalmente com o objetivo de prevenção da violência no espaço onde se transita.

$\mathrm{E}$, finalmente, a psicologia pode contribuir nas pesquisas e intervenções com os acidentados visando à reabilitação, estabelecendo investigações nas relações no campo das organizações, e até mesmo intervenções clínicas.

Antecipando o debate, o trânsito demanda a formação de profissionais para atuar com pesquisas que permitam subsidiar políticas públicas e intervenções profissionais tanto na prevenção, quanto junto aos 
grupos envolvidos com a violência no trânsito. Essa atuação pode focalizar o tradicional triplo "E" da segurança do trânsito: engenharia, educação e esforço legal (engineering, education, enforcement) ou ampliar as perspectivas incluindo outras formas de desvelar a participação da psicologia na compreensão do comportamento humano no trânsito.

Para finalizar o contexto dessa abordagem é obrigatório citar a definição de Psicologia do Trânsito proposta por Rozestraten (1988):

Uma área da psicologia que estuda, através de métodos científicos válidos, os comportamentos humanos no trânsito e os fatores e processos externos e internos, conscientes e inconscientes que os provocam ou os alteram. Em síntese: é o estudo dos comportamentosdeslocamentos no trânsito e suas causas. (p. 9)

Essa definição destaca a amplitude de investigação pertinente ao campo da Psicologia do Trânsito, indicando a possibilidade de utilização de diferentes abordagens, já que faz referência a processos inconscientes, cuja fundamentação deve ser buscada junto à psicanálise. Rozestraten (1981) já abordava a complexidade do comportamento humano no trânsito, enfatizando que ele inclui processos de atenção, detecção, diferenciação, percepção, processamento de informações, memória, aprendizagem, conhecimento de normas e símbolos, motivação, tomada de decisões; inclui também automatismos perceptomotores, como manobras rápidas e capacidade de reagir prontamente, antecipando situações (em curvas, cruzamentos e lombadas); além disso, há atitudes em relação aos outros usuários, aos fiscalizadores, às normas de segurança e a uma infinidade de outros fatores e situações. Assim, a amplitude do campo de investigação vai desde a psicofísica e psicofisiologia até processos decisórios e cognitivos, utilizando as teorias da psicologia (Rozestraten, 1981, 1988). Cada um desses aspectos pode ser objeto de estudo subsidiando intervenções visando manter a integridade das pessoas.

Vamos abordar alguns desses focos de investigação e intervenção, tal como têm sido desenvolvidos na Universidade Federal do Paraná.

\section{Trajetória histórica do Núcleo de Psicologia do Trânsito da Universidade Federal do Paraná (NPT-UFPR)}

Algumas histórias fazem parte do folclore do Núcleo de Psicologia do Trânsito da Universidade Federal do Paraná (NPT/UFPR) e refletem a ausência de entendimento da psicologia como estudo do comportamento humano, que é uma área de conhecimento que abrange inúmeras atividades: onde houver seres humanos, a psicologia pode propiciar uma contribuição. E nos espaços onde o comportamento humano tem se destacado como central, como é o caso do trânsito, maior ainda é a possibilidade de atuação com base nos referenciais da psicologia.

Para iniciar a abordagem do tema, o depoimento de uma das primeiras alunas do NPT/UFPR ilustra a descoberta de um campo de atuação até então pouco explorado pelos psicólogos no Brasil. Era o final do seu ano de atividades de pesquisa no Núcleo, e ela confessou:

Quando cheguei aqui no NPT, eu me perguntava: 'O que a Psicologia tem a ver com trânsito? Nada!' Eu não via nenhuma relação. Hoje, depois desse ano, da pesquisa e do conhecimento da área, eu digo 'trânsito é só psicologia! Trânsito é só comportamento humano!

Há outro relato marcante: uma aluna foi contemplada com uma bolsa de estudos e teria que exercer atividades no NPT. Depois de um ano ela confessou: "Quando eu ganhei a bolsa e soube que teria que trabalhar no NPT eu chorei a noite inteira de desgosto: Trabalhar com trânsito? Que coisa mais sem graça!'. Hoje essa aluna está em seu quarto ano no NPT, já tendo atuado em projetos de pesquisa e extensão.

Como surgiu esse espaço diferenciado de ensino, pesquisa e extensão que começou a despertar o interesse dos alunos? O surgimento da linha de pesquisa "Psicologia do Trânsito" no Mestrado em Psicologia da UFPR, e também do grupo de pesquisa no Conselho Nacional de Desenvolvimento Científico e Tecnológico $(\mathrm{CNPq})$ pode ser elucidado através da história da construção do NPT/UFPR.

Em março de 2001, após a realização do Doutorado Interdisciplinar em Ciências Humanas, na área "Sociedade e Meio Ambiente", na UFSC, foi possível constatar novos projetos e perspectivas para o curso de Psicologia. Diversos laboratórios haviam sido criados. Um deles, sob a coordenação do Prof. Eduíno Sbardelini Filho, denominava-se Laboratório de Avaliação Psicológica. Se o Prof. Reinier Rozestraten foi o pai da Psicologia do Trânsito no Brasil, no Paraná esse papel cabe ao Prof. Eduíno, que já atuava com a Psicologia do Trânsito e implantou essa disciplina optativa no curso de Psicologia da UFPR. Foi estruturado naquela época, como uma das atividades do laboratório, o Projeto Transformando o Trânsito, que foi 
planejado durante todo o ano de 2001, com a ajuda dos alunos da graduação em Psicologia. Fazem parte desse período vários alunos que continuaram a auxiliar nos trabalhos do NPT mesmo depois de formados, como voluntários. Em 2002, o projeto foi aprovado e registrado pela Pró-Reitoria de Extensão e Cultura, sob o número 316/02 (Thielen, 2002b), e ainda hoje, 2011, é o coração do NPT.

O Projeto Transformando o Trânsito (PTT) foi criado a partir da preocupação com os altos índices de mortalidade de jovens, na faixa etária característica da universidade. A intervenção teria que ser inovadora e deveria atuar sobre aquilo que foi definido como a base orientadora dos comportamentos: a concepção sobre o trânsito. Esse deve ser o foco de intervenções para promover transformações no trânsito. A pesquisa sobre excesso de velocidade (Thielen, 2002a) identificou que não havia diferenças entre motoristas multados ou não, em relação às percepções sobre o trânsito: ambos os grupos deixaram evidente o individualismo que marca suas concepções, decisões e ações no ambiente do trânsito. Havia, pois, uma demanda pelo trabalho com os jovens, que pudesse atingir exatamente esse individualismo. O grupo que consolidou a proposta de projeto buscava maneiras de despertar a reflexão dos participantes, de forma a propiciar uma compreensão das consequências do individualismo e da necessidade de fomentar uma nova concepção de trânsito que pudesse ser transformadora: ela teria que incorporar a dimensão coletiva nas decisões e ações individuais. Foi proposto um Encontro, batizado "Dirija sua Vida" pelos integrantes da equipe do NPT, que deveria promover a discussão com os jovens sobre trânsito. O termo Encontro é baseado na proposta de Rogers (1961/2009a, 1970/2009b) e os membros da equipe atuam como facilitadores das atividades dos grupos participantes do projeto.

O Encontro "Dirija sua Vida" foi estruturado em cinco momentos: 1) apresentação da equipe e da justificativa do projeto aos jovens dos primeiros anos; 2) um jogo com fichas coloridas, denominado Metaphor (Ferreira \& Corte, 1978; Thielen, Ricardi Neto, Hartmann, \& Soares, 2005), que tem demonstrado seu poder como uma metáfora do trânsito, pois recria situações do cotidiano e permite vivenciar etapas importantes (individualismo e conflitos; confronto com a autoridade e as regras; organização e cooperação) para consolidar a reflexão centrada na relação entre comportamento individual e comportamento coletivo, entre espaço público e espaço privado; 3) discussão em pequenos grupos, instigando a análise das relações entre a vivência no jogo e o trânsito; 4) incentivo para compartilhar as discussões no grande grupo; 5) elaboração de compromisso pessoal para a transformação do trânsito, baseado nas reflexões decorrentes da atividade.

A partir da estruturação do Projeto Transformando o Trânsito foi criado o NPT, pois a preocupação com o trânsito de uma forma mais ampla, que não aquela restrita à avaliação psicológica, começava a tomar corpo. A princípio, dentro do Laboratório de Avaliação Psicológica: Eduíno coordenava o Laboratório e eu o NPT. A partir da aposentadoria do Prof. Eduíno, o laboratório restou desativado e o NPT seguiu sua trajetória, incorporando a parcela de avaliação voltada para a análise do comportamento humano em situação de trânsito.

O NPT foi se estruturando, projetos de pesquisa foram sendo propostos, diversos alunos foram se integrando às atividades de extensão e pesquisa. O Projeto Transformando o Trânsito foi gerando pesquisas, monografias, apresentação em eventos, agregando cada vez mais alunos, despertando o interesse de todos quantos tomavam conhecimento sobre as inúmeras possibilidades de trabalho com a psicologia do trânsito e sobre o uso do jogo para fomentar a reflexão sobre trânsito, num espaço de apenas duas horas/aula. Consolidou-se como uma proposta inovadora. Além disso, essa nova forma de atuar com a Psicologia do Trânsito foi conquistando alunos, foi adquirindo credibilidade a partir das investigações que realizava e foi sendo chamada a divulgar os conhecimentos sobre o comportamento humano no trânsito.

Foi o Projeto Transformando o Trânsito que fez nascer o NPT. É possível afirmar que a história do NPT é a história do Projeto Transformando o Trânsito.

Em 2006, José Carlos Belotto, técnico da universidade, propôs a articulação do NPT numa outra proposta de extensão: o Programa Ciclovida, coordenado por ele que passou a integrar o NPT. A proposta foi consolidada e registrada em 2008 (Belotto, 2008). Como também articulava a participação de outros departamentos da UFPR, como Arquitetura e Urbanismo e Educação Física, além de outros Cursos como Engenharia Ambiental, Design e Engenharia da Produção, o NPT ampliou sua atuação. Em 2009, o Programa Ciclovida consolidou-se como um Programa Institucional.

Em 2008, foi criado o Grupo de Pesquisa "Psicologia do Trânsito" no CNPq e foi proposta a Linha de Pesquisa "Psicologia do Trânsito: avaliação e preven- 
ção" para o Mestrado em Psicologia, que teve seu início em 2009.

Em 2011, o NPT atende à graduação e pósgraduação em Psicologia nas atividades de ensino, pesquisa e extensão. Orienta bolsistas da UFPR, CAPES, REUNI, CNPq e Fundação Araucária, além de voluntários da graduação e pós-graduação (mestrado, especialização, iniciação científica, extensão, monitoria). Um aluno do Mestrado, Diogo P. Soares, bolsista REUNI, atuou durante 2009 e 2010 com treinamento e desenvolvimento de competências dos integrantes do NPT para atuar no Projeto Transformando o Trânsito organizando um artigo (em submissão) que aborda a estrutura de atuação dos facilitadores junto aos grupos.

\section{Concepção básica norteadora das investigações propostas pelo NPT}

A teoria de sistemas (Bertalanffy, 1973) fornece o arcabouço a partir do qual as pesquisas no NPT são delineadas, ainda que abordagens psicológicas diversas possam contribuir para orientar a interpretação de dados específicos ou fomentar debates que ampliam a compreensão sobre o comportamento humano no trânsito.

É importante destacar que o ser humano toma decisões sobre a maneira de se comportar. E são essas decisões que farão toda a diferença, resultando em mais riscos ou menos riscos para si e para os demais. Portanto, um dos focos de investigação tem se voltado para os fatores que interferem na tomada de decisão.

A visualização do comportamento humano como sistema (Thielen, Hartmann, \& Soares, 2008) indica que há no mínimo quatro componentes básicos: insumos, processo, produto e feedback. Insumos alimentam o funcionamento do sistema, constituindo-se em componentes fundamentais cujas características irão orientar a qualidade dos produtos ou resultados do sistema. Processo é a maneira característica de operar do sistema; compõe-se de diversas etapas cujo seguimento permite compreender o funcionamento do sistema, pela análise do fluxo de energia. Produto é o resultado do sistema, podendo ser caracterizado como aquilo que o sistema gera. Feedback é a ação necessária para que o sistema continue existindo, servindo como fonte de informação para que ajustes sejam feitos, tanto para aprimorar o processo, quanto para avaliar os insumos (qualidade, quantidade, tipo, entre outras características), tendo como referencial o produto do sistema. O feedback se constitui na informação sobre o resultado do funcionamento do sistema, permitindo ajustes.
A autora Fela Moscovici (1985) aborda "a importância do feedback nas relações interpessoais" indicando como essas informações são fundamentais para permitir trocas e aprimorar o desempenho humano. Katz e Kahn (1987) detalham outras características dos sistemas sociais, que podem ser utilizadas também na compreensão do comportamento humano no trânsito.

Traduzindo a teoria (de forma simplificada) para o comportamento humano no trânsito, é possível analisar os fatores que afetam o indivíduo que toma as decisões e age no trânsito. Assim, a ação é o produto do sistema. Exemplos de ações: "avançar o sinal vermelho", "atravessar na faixa", "insultar pedestres", "atropelar pedestres", "evitar colisões", "dirigir sob influência de álcool", "exceder a velocidade", "realizar ultrapassagens perigosas", "ceder passagem", "não parar sobre a faixa de pedestres", entre outras. Todas elas são produto do sistema comportamento humano. Algumas dessas ações exemplificadas são caracterizadas como comportamentos de risco.

Quais são os insumos que permitem como resultado final essas ações?

É possível identificar diversos insumos e até mesmo classificá-los para fins didáticos em internos (atenção; memória; aprendizagem; motivação; personalidade; valores; sentimentos; percepção; percepção de riscos; entre outros) e externos, (fatores ambientais; físicos; veículo; via - sinalização; legislação; demais integrantes; entre outros) enfatizando que não se trata de fatores isolados, mas de fatores em interação. Além disso, a constituição dos fatores internos é sempre mediada pelo ambiente. Cada um desses fatores ou mesmo grupos de fatores ou sua interação podem ser objeto de pesquisa, elucidando como sustentam, alimentam, instigam, fortalecem e motivam comportamentos de risco.

E o processamento dessas informações? O processamento dessas informações culmina com a tomada de decisão. E essa decisão no trânsito pode ser visualizada em duas direções opostas - arriscar ou não - que podem fazer a diferença entre a vida e a morte. $\mathrm{O}$ processo indica as diversas etapas que fundamentam a tomada de decisão: detecção das variáveis envolvidas; decodificação das informações a partir de fatores individuais, grupais, culturais ou ideológicos; seleção de estímulos; análise das variáveis; antecipação das consequências da ação; análise do jogo de forças presente na situação; compreensão da relação entre variáveis e contexto; atribuição de significado às variáveis. A tomada de decisão a partir desse jogo de interações 
ocorre sob influência de fatores cognitivos e afetivos, e, no trânsito, ocorre em fração de segundos. Estimase em $3 / 4$ de segundo o tempo de reação, e para efeito de cálculo se utiliza o arredondamento para 1 segundo. Significa que esse é o tempo que uma pessoa leva para emitir uma resposta frente a uma situação de emergência como frear repentinamente com o surgimento de um veículo cruzando a via preferencial na qual está transitando. Se o carro estiver a $80 \mathrm{~km} / \mathrm{h}$ significa que a pessoa vai processar todas as informações em 1 segundo, para depois reagir, pisando no freio. E durante esse tempo de reação o carro continua a se deslocar, na mesma velocidade, significando que ele percorre $22 \mathrm{~m}$ durante o tempo de reação da pessoa, ou seja, enquanto ela está pensando e decidindo o que fazer. Significa que somente depois de ter percorrido esses $22 \mathrm{~m}$ é que a pessoa vai pisar no freio e então o processo de frenagem tem início, fazendo com que o carro se desloque aproximadamente mais 30 metros (que é a distância de frenagem para carros, em condições climáticas boas, e com pista em boas condições). Portanto, a distância total até a parada do veículo que transita a $80 \mathrm{~km} / \mathrm{h}$ é de $52 \mathrm{~m}$. Enquanto o indivíduo processa as informações (identifica os riscos, apreende o significado do perigo, pondera as alternativas, aquilata o medo) e até tomar a decisão, o carro continua se deslocando, durante o período designado por tempo de reação. E esse tempo de reação (TR) de 1s vai significar que quanto mais elevada é a velocidade, maior a distância percorrida enquanto o indivíduo está processando o que vai fazer. Isso significa que a elevação da velocidade sempre potencializa os riscos, em função do tempo de reação associado a ela: 1s (TR) a $80 \mathrm{~km} / \mathrm{h}$ significa $22 \mathrm{~m}$ percorridos; $1 \mathrm{~s}$ (TR) a $110 \mathrm{~km} / \mathrm{h}$ significa 31 metros percorridos; $1 \mathrm{~s}$ (TR) a $150 \mathrm{~km} / \mathrm{h}$ significa 42 metros percorridos. Ou seja, a elevação da velocidade significa sempre uma distância maior percorrida durante o tempo de reação, durante o tempo de processamento dos insumos, até a tomada de decisão, portanto, há muito mais riscos envolvidos.

Desnecessário enfatizar que o uso de quaisquer substâncias, como álcool e outras drogas, ou mesmo o uso de equipamentos que disputem a atenção do motorista, podem aumentar esse tempo de reação, potencializando ainda mais os riscos. A título de exemplo, se o efeito da ingestão de álcool afetar um determinado indivíduo em $1 / 2$ segundo, significa um aumento de $50 \%$ no tempo de reação $\left(1 \frac{1}{2} \mathrm{~s}\right)$. No exemplo anterior, se o veículo estiver a $80 \mathrm{~km} / \mathrm{h}$ significa que ele vai percorrer $33 m(22 m+11 m)$ durante o tempo de reação e a distância total até a parada será de $63 \mathrm{~m}$. Conforme Dotta (1998, p. 19), "o condutor terá que administrar os riscos que se aproximam, à razão de 28 metros por segundo quando dirige a $100 \mathrm{~km} / \mathrm{h}$. As situações no trânsito se tornam graves, ameaçadoras e incontroláveis em 3 ou 4 segundos". Portanto, o processamento das informações é uma etapa fundamental para que a tomada de decisão seja compatível com a segurança. E o processamento depende dos insumos.

Após o processamento dos insumos que culmina com a tomada de decisão e a realização dos atos, o feedback é representado pelas informações que atingem o motorista após seu comportamento. Se ele adotou um comportamento de risco, isso pode resultar em: colisão, morte, atropelamento, multa, reações negativas de outros motoristas ou pedestres, reações de familiares e amigos, e todas essas informações incidem sobre o motorista permitindo a ele analisar equívocos nos insumos (ex.: desconhecimento da legislação) ou no processamento das informações (ex.: cálculo equivocado de distâncias em ultrapassagens).

Estudos que focalizam insumos, processo, produto ou feedback podem contribuir para a prevenção e intervenção em comportamentos no trânsito. Além disso, cada um dos focos pode ser tratado como sistema, identificando insumos, processo, produto e feedback. É característica dos sistemas a possibilidade de visualização em subsistemas podendo cada um deles ser estudado, respeitando-se cada um dos níveis.

A existência de diferentes níveis de complexidade na natureza e a tentativa das diferentes disciplinas de compreender os fenômenos tem mostrado a busca de correlações entre variáveis desde que pertencentes ao mesmo nível, e abordagens reducionistas e holísticas são antagônicas em relação aos fenômenos que envolvem diferentes níveis de complexidade. Ávila-Pires (1998), Bergandi (1992) e Bertalanffy (1973) alertam para a existência de propriedades emergentes não acessíveis aos processos analíticos, e que se evidenciam a partir da dinamicidade do sistema.

A perspectiva sistêmica que aborda certos fenômenos como propriedades emergentes pode desvelar as múltiplas interações que se apresentam nos fenômenos complexos. O trânsito é um deles. Embora haja diversos níveis de análise e suas particularidades, é preciso compreender que a análise do fenômeno trânsito envolve propriedades que emergem em decorrência da interação entre os diversos níveis. $\mathrm{O}$ exemplo a seguir 
ilustra essa idéia da interação e potencialização das influências entre os integrantes do sistema.

(...) quando se fala em "curva perigosa" pode-se analisar que ela seja perigosa em determinadas circunstâncias que remetem à via (chuva, condições precárias de iluminação, condições do pavimento, traçado geométrico, composição do pavimento, sinalização horizontal e vertical, entre outras), ao veículo (condições de conservação de pneus, sistema de freios, sistema de iluminação entre outras) ou ao motorista (condições físicas plenas, principalmente visão, estado de alerta, conhecimento sobre processos de frenagem e derrapagem em diferentes tipos de pavimentos e condições climáticas, conhecimento de refração de luz em diferentes situações - neblina, ao cruzar veículos, direção do sol - ou conhecimento sobre as condições do próprio veículo e sobre a via, além das variáveis psicológicas). Mas, o que torna uma curva perigosa não é somente o traçado geométrico - embora possa ser considerado o fator mais relevante e que determina a denominação - mas a relação que se estabelece entre as condições da via, do veículo e do motorista. Ou seja, supondo que o veículo esteja em boas condições, se numa "curva perigosa" o motorista reduz a velocidade, as condições "perigosas" poderão ser minimizadas; se, no entanto, ele imprime uma alta velocidade o perigo é iminente. Isto significa que uma "curva perigosa" necessita de condições da via, do veículo, do motorista e da interação entre eles para se efetivar. Isto sem fazer referência explícita aos demais motoristas que trafegam na mesma via (numa "curva perigosa", à noite, com chuva, em via de mão dupla, cruzando com outro veículo com luz alta, o perigo é potencializado e uma baixa velocidade pode contrabalançar o risco). Sintetizando, embora o exemplo não esgote os fatores envolvidos (e seja caricatural), fornece o arcabouço básico de análise do fenômeno, já que explicita a importância de se considerar não só variáveis isoladas, mas, principalmente a relação que se estabelece entre elas. (Thielen, 2002a, pp. 6-7)

A partir da perspectiva sistêmica é possível centralizar as análises nas interações entre os diversos componentes do sistema, permitindo mapear a rede de fatores que contribuem para os comportamentos de risco. Entre esses fatores, aqueles relativos à percepção de riscos têm se mostrado muito relevantes, congregando esforços de investigação, abordando diferentes grupos de integrantes, como motoristas de carro de passeio, motoristas de ônibus, taxistas, entre outros.

\section{Perspectivas de pesquisa no NPT-UFPR}

Há diversos temas que têm orientado algumas pesquisas desenvolvidas e em desenvolvimento no NPT-
UFPR: desenvolvimento moral, autoeficácia, competências do motorista, comportamento de risco, uso de álcool, e, principalmente o tema da percepção de riscos tem sido proposto como fundamentação para diversos projetos.

Cada um desses temas pode ser estudado a partir de diferentes perspectivas, mas têm sido privilegiadas algumas em detrimento de outras. No caso dos estudos abordando a moralidade, a perspectiva de Kolhberg (1981) predominou até o momento. Os estudos sobre o conceito de autoeficácia e o comportamento no trânsito tomaram como base Bandura (1986, 1995, 1997). Mas os estudos desses diferentes temas não se limitam a apenas uma perspectiva teórica, pois diferentes abordagens podem contribuir para ampliar o conhecimento sobre o comportamento humano, suas motivações, seus desejos. Assim é que algumas interlocuções já foram empreendidas a partir da perspectiva da psicopatologia fundamental (Grassi \& Thielen, 2006), da psicanálise (Pinheiro, 2006, 2007) e também uma leitura a partir da abordagem junguiana (Serbena, 2007), em diferentes espaços de discussão científica. Ou seja, diferentes abordagens podem contribuir para o estudo do comportamento humano em situação de trânsito.

O primeiro tema investigado pelo NPT focalizou a percepção de motoristas sobre excesso de velocidade (Thielen, 2002a). E, com essa perspectiva, o tema da percepção de riscos foi se consolidando como uma das opções preferenciais de estudo. O objetivo inicial era comparar as percepções de motoristas multados e não multados sobre excesso de velocidade. Os resultados indicaram que não havia diferença de percepção sobre excesso de velocidade entre os dois grupos. Ambos eram muito individualistas nas suas concepções. E as respostas características dos motoristas multados para justificar suas infrações eram: "eu não sabia que ali tinha radar", "não vi o radar". Essas respostas instigaram sua análise a partir do referencial da teoria de Kolhberg, que consolidou os estudos sobre desenvolvimento moral. Com base nos estágios de desenvolvimento moral, diversos instrumentos foram construídos e "nas décadas de 1960 e 1970 mais da metade de todas as publicações lançadas nos Estados Unidos no campo da psicologia individual e social faziam menção à Kolhberg" (Freitag, 1997, p. 192).

Assim, o tema do desenvolvimento moral também tem sido objeto de estudo no NPT, na relação com o comportamento no trânsito. Numa primeira estruturação de pesquisa, Kohlberg constituiu a base teórica de um projeto desenvolvido em diversas etapas, por alu- 
nos integrantes de iniciação científica: 1) a primeira delas foi utilizar o referencial de Kolhberg para analisar as respostas dos motoristas multados por excesso de velocidade, que resultou na caracterização do estágio 1 (Kolhberg, 1981) como predominante nas respostas $(75,51 \%)$ e também na delimitação de comportamentos no trânsito com base nos 6 estágios propostos por Kolhberg (Polli, 2004); 2) a segunda etapa consistiu no estudo de diversos instrumentos verificando sua pertinência para a situação de trânsito: $M o$ ral Judgement Test - MJT, de Lind (1998); Social Moral Reflection - SROM; Defining Issues Test-2 DIT (Shimizu, 2004); 3) na terceira etapa, alguns instrumentos foram propostos com base em Kolhberg e a partir dos modelos de instrumentos anteriormente estudados. Os resultados indicaram limitações na aplicação da teoria de desenvolvimento moral baseada nas justificativas, pois estas se aplicam a ações infratoras ou não (Polli, Thielen, Hartmann, \& Soares, 2010). Continua aberta a possibilidade do uso de outras teorias que abordem a perspectiva da moralidade para a compreensão do comportamento humano no trânsito, consolidando um foco importante de investigação.

Outras investigações pontuais têm focalizado comportamentos específicos, buscando compreender suas motivações e interações. É o caso do comportamento de "estacionar em local proibido", que foi estudado por uma aluna de graduação, no Centro Politécnico da UFPR. Também foram feitos alguns estudos-piloto focalizando as características do "bom motorista", na perspectiva de alguns integrantes do trânsito (motoristas de ônibus; taxistas; ciclistas; motoristas de carro de passeio). Comportamentos de ciclistas também têm sido objeto de investigação.

A vertente mais consolidada refere-se aos fundamentos propostos nos estudos sobre percepção de riscos, embora os estudiosos tenham focalizado outros objetos que não o trânsito (Lima, 1995, 1998, 2005; Renn, 2004; Slovic, 1982, 1987). As investigações empreendidas pelo NPT têm corroborado os mesmos grupos de fatores pesquisados em outras vertentes, indicando que os riscos afetam diversos comportamentos do cotidiano: uso de tabaco, álcool e outras drogas, alimentação, comportamento sexual, esportes, aspectos econômicos e trânsito. Conforme Dotta (1998, p.14), "os acidentes de trânsito são decorrentes dos riscos que o ser humano aceita" e, para Wilde (2005), há sempre uma "quantidade" de risco que o ser humano está disposto a assumir e que se eleva na medida em que sistemas seguros são implementados. No trânsito, os riscos são permanentes.
Para Slovic, Fischhoff e Lichtenstein (1982) esforços para promover mudanças, sejam pessoais, organizacionais ou políticas dependem da forma como as pessoas reagem aos riscos que percebem. Se essas percepções forem equivocadas, os esforços podem ser malogrados. Compreender os mecanismos subjacentes às percepções de risco possibilita identificar como são construídas, mantidas e fortalecidas, tornando possível planejar estratégias de intervenção que promovam conscientização em relação à quantidade de risco que as pessoas estão dispostas assumir. Wilde (2005, p. 302) orienta sobre a necessidade de criar meios para "motivar o indivíduo para que ele queira estar seguro", ou seja, que ele tenha motivos para querer se preservar para um futuro próximo ou distante, adotando um comportamento globalmente mais seguro em todos os seus comportamentos, incluindo o trânsito. Portanto, o estudo da percepção de risco pode elucidar as decisões que são tomadas pelos indivíduos quando estão no trânsito e podem auxiliar na comunicação ou intervenção visando à prevenção.

Alguns fatores estudados no NPT têm sido indicados como importantes na constituição e fortalecimento de percepções equivocadas: familiaridade; consciência do risco; confronto entre risco objetivo e risco percebido; gravidade do risco; extensão dos danos; responsabilidade pela prevenção; aceitação do risco; certeza sobre o impacto dos riscos; confiança nas fontes de informação (Kates, Burton, \& White, 1978; Langer, 1975; Lima, 1995, 1998; Slovic, 1987; Thielen, 2002a; Thielen, Hartmann, \& Soares, 2008; Thielen \& Soares, 2009; Weinstein, 1981; White, 1974). Investigar como cada um desses fatores interfere na percepção de riscos, pode permitir um planejamento de intervenções mais eficazes para reduzir tanto as ações como o agravamento das consequências das ações arriscadas empreendidas no trânsito. Cada um dos fatores listados atesta a complexidade que o risco assume no comportamento das pessoas, permitindo desenvolver processos educativos que possam incorporar aspectos psicológicos que constituem essas percepções.

\section{CONSIDERAÇÕES FINAIS}

Busquei esboçar a trajetória percorrida pelo NPT desde antes de sua fundação, indicando que a proposta norteadora de atuação com a psicologia do trânsito amplia as perspectivas tradicionais, incorporando dimensões para além da avaliação psicológica e, ao mesmo tempo, deixa em aberto inúmeras possibilidades, indicando a interface com outras áreas de conhecimento. 
Investigar o comportamento humano no trânsito é o escopo das diferentes propostas que têm consolidado uma atuação voltada para a orientação da população. A centralidade das investigações na percepção dos riscos não limita a amplitude de estudos que podem ser empreendidos no âmbito do trânsito, dos transportes, da mobilidade, das políticas públicas e do desenvolvimento urbano.

\section{REFERÊNCIAS}

Ávila-Pires, F. D. (1998). Medical ecology, holism and circular reasoning in medicine. Em C. Susanne \& L. Gallé (Orgs.), Ecotechnie and sustainable development (pp. 205-218). Szeged: Officina.

Bandura, A. (1986). Social foundations of thought and action: A social cognitive theory. Englewood Cliffs, NJ: Prentice-Hall.

Bandura, A. (Org.) (1995). Self-efficacy in changing societies. New York: Cambridge University Press.

Bandura, A. (1997). Self-efficacy: The exercise of control. New York: W. H. Freeman.

Belotto, J. C. (2008). Programa Ciclovida. Curitiba: Universidade Federal do Paraná, Pró-Reitoria de Extensão e Cultura. (Projeto de Extensão sob registro 072/08).

Bergandi, D. (1992). Fundamentals of ecology de E. P. Odum: Véritable "approcheholiste" ou reductionnisme masqué?. Bulletin d'Écologie, 24, 57-68.

Bertalanffy, L. von (1973). Teoria geral dos sistemas (A. Simões, Trad.). Petrópolis: Vozes.

Dotta, A. (1973). Condutor defensivo. Porto Alegre: Sagra Luzzatto.

Ferreira, M. S., \& Corte, J. C. (1978). Metaphor: Uma experiência com grupos. Referência em Planejamento, 3(8), 62-65.

Freitag, B. (1997). Itinerários de Antígona: A questão da moralidade. Campinas: Papirus.

Grassi, M. V. F. C., \& Thielen, I. P. (2006, setembro). Pathos e solidariedade. Em Associação Universitária de Pesquisa em Psicopatologia Fundamental (Org.), Anais do II Congresso Internacional de Psicopatologia Fundamental e VIII Congresso Brasileiro de Psicopatologia Fundamental. Belém: Associação Universitária de Pesquisa em Psicopatologia Fundamental. Retirado em 20 de janeiro de 2010, de http://www.fundamental psychopathology.org/anais2006/4.38.3.3.htm

Hoffman, M. H., \& Cruz, R. M. (2003). Síntese histórica da psicologia do trânsito. Em M. H. Hoffman, R. M. Cruz, \& J. C. Alchieri (Orgs.), Comportamento humano no trânsito (pp. 17-29). São Paulo: Casa do Psicólogo.

Kates, R. W., Burton, I., \& White. G. F. (1978). The environment as hazard. New York: Oxford University Press.

Katz, D., \& Kahn. R. L. (1987). Psicologia social das organizações (A. Simões, Trad.). São Paulo: Atlas.

Kohlberg, L. (1981). Essays on moral development: The philosophy of moral development. San Francisco: Harper \& Row.

Langer, E. J. (1975). The illusion of control. Journal of Personality and Social Psychology, 32, 311-328.

Lima, M. L. (1995). Viver com o risco: Abordagens da psicologia social ambiental. Inforgeo, 9, 39-54.
Lima, M. L. (1998). Factores sociais na percepção de riscos. Psicologia, 12, 11-28.

Lima, M. L. (2005). Percepção de riscos ambientais. Em L. Sockza, Contextos humanos e psicologia ambiental (pp. 203245). Lisboa: Fundação Calouste Gulbenkian.

Lind, G. (1998). Introduction to the moral judgment test, MJT. Retirado em 1 de setembro de 2004, de http://unikonstanz.de/ag-moral/

Marín, I., \& Queiroz, M. S. (2000). A atualidade dos acidentes de trânsito na era da velocidade: Uma visão geral. Cadernos de Saúde Pública, 16, 7-21.

Monterde i Bort, H. (2008). O modelo de avaliação médicopsicológica: Desenvolvimento atual e críticas. Em A. S. Bianchi (Org.), Humanidade e trânsito: Desafios para um futuro sustentável (pp. 101-132). Curitiba: Conselho Regional de Psicologia.

Moscovici, F. (1985). Desenvolvimento interpessoal (3 ${ }^{\mathrm{a}}$ ed.). Rio de Janeiro: LTC.

Organización Mundial de la Salud (2010). Informe mundial sobre prevención de los traumatismos causados por el tránsito. Retirado em 20 de janeiro de 2010, de http://www.who.int/violen ce_injury_prevention/publications/road_traffic/world_report/es /index.html

Pinheiro, N. N. B. (2006, setembro). Pulsões e transicionalidade: Reflexões sobre a violência no trânsito. Em Associação Universitária de Pesquisa em Psicopatologia Fundamental (Org.), Anais do II Congresso Internacional de Psicopatologia Fundamental e VIII Congresso Brasileiro de Psicopatologia Fundamental. Belém: Associação Universitária de Pesquisa em Psicopatologia Fundamental. Retirado em 20 de janeiro de 2010, de http://www.fundamentalpsychopathology.org/anais 2006/4.38.3.2.htm

Pinheiro, N. N. B. (2007, setembro).A agressividade como potência criativa e destrutiva: Reflexões sobre a violência no trânsito a partir da psicanálise. Em Universidade Estadual de Maringá (Org.), Anais do III Congresso Internacional de Psicologia. Maringá: UEM. Retirado em 20 de janeiro de 2010, de http://www.cipsi.uem.br/anais2007/trabalhos/7.pdf

Polli, G. M. (2004). A influência do nível de desenvolvimento moral no comportamento de motoristas infratores. Monografia de graduação não-publicada, Universidade Federal do Paraná, Curitiba.

Polli, G. M., Thielen, I. P., Hartmann, R. C., \& Soares, D. P. (2010). Excesso de velocidade no trânsito: Análise sob a perspectiva da moralidade. Psicologia: Ciência e Profissão, 30, 8697.

Renn, O. (2004). Perception of risks. Toxicology Letters, 149, 405-413.

Risser, R. (2004). Estudos sobre a avaliação psicológica de motorista (R. J. A. Rozestraten, Trad.). São Paulo: Casa do Psicólogo.

Rogers, C. (2009a). Tornar-se pessoa (6 ${ }^{\mathrm{a}}$ ed.) (M. J. C. Ferreira e A. Lamparelli, Trad.). São Paulo: Martins Fontes. (Original publicado em 1961)

Rogers, C. (2009b). Grupos de encontro (9a ed.) (J. L. Proença, Trad.). São Paulo: Martins Fontes. (Original publicado em 1970)

Rozestraten, R. J. A. (1981). Psicologia do trânsito: O que é e para que serve. Psicologia: Ciência e Profissão, 1, 141-143. 
Rozestraten, R. J. A. (1988). Psicologia do trânsito: Conceito e processos básicos. São Paulo: EPU.

Serbena, C. A. (2007, setembro). O automóvel, a modernidade e a busca da totalidade. Em Universidade Estadual de Maringá (Org.), Anais do III Congresso Internacional de Psicologia. Maringá: UEM. Retirado em 20 de janeiro de 2010, de http://www.cipsi.uem.br/anais2007/trabalhos/145.pdf

Shimizu, A. M. (2004). Defining Issues Test-2: Fidedignidade da versão brasileira e ponderações acerca de seu uso em pesquisa sobre moralidade. Psicologia: Reflexão e Crítica, 17, 5-14.

Slovic P., Fischhoff B., \& Lichtenstein S. (1982). Facts versus fears: Understanding perceived risk. Em D. Kahneman, P. Slovic \& A. Tversky (Orgs.), Judgment under uncertainly: Heuristics and biases (pp. 463-489). Cambridge: Cambridge University Press.

Slovic, P. (1987). Perception of risk. Science, 236, 280-285.

Thielen, I. P. (2002a). Percepções de motoristas sobre excesso de velocidade no trânsito de Curitiba. Tese de doutorado nãopublicada, Universidade Federal de Santa Catarina, Florianópolis.

Thielen, I. P. (2002b). Projeto Transformando o Trânsito. Curitiba: Universidade Federal do Paraná, Pró-Reitoria de Extensão e Cultura. (Projeto de Extensão sob registro 316/02).
Thielen, I. P., Ricardi Neto, M., Soares, D. P., \& Hartmann, R. C. (2005). Metaphor: O jogo do trânsito. Psicologia: Pesquisa \& Trânsito, 1, 45-52.

Thielen, I. P., Hartmann, R. C., \& Soares, D. P. (2008). Percepção de risco e excesso de velocidade. Cadernos de Saúde Pública, 24, 131-139.

Thielen, I. P., \& Soares, D. P. (2009). Percepção de riscos: sexo, drogas e ... (rock'n'roll) trânsito. Em A. S. Bianchi (Org.), Humanidade e trânsito: Desafios para um futuro sustentável (pp. 133-146). Curitiba: Conselho Regional de Psicologia.

Weinstein, N. D. (1981). Unrealistic optimism about future life events. Journal of Personality and Social Psychology, 39, 806820.

Wilde, G. J. S. (2005). O limite aceitável de risco: Uma nova psicologia sobre segurança e saúde: $O$ que funciona? $O$ que não funciona? E por quê?? (R. J. A. Rozestraten, Trad.). São Paulo: Casa do Psicólogo.

White, G. F. (1974). Natural hazards: Local, national, global. New York: Oxford University Press.

\section{Sobre a autora:}

Iara Picchioni Thielen - Psicóloga, Doutora em Ciências Humanas pela Universidade Federal de Santa Catarina. Professora do Departamento de Psicologia da Universidade Federal do Paraná, na graduação e pós-graduação. Fundadora e coordenadora do Núcleo de Psicologia do Trânsito da UFPR.

Endereço eletrônico: iara.thielen@gmail.com 